\title{
Update on the Genetic Basis of Sudden Unexpected Death in Epilepsy
}

\author{
Monica Coll ${ }^{1, *}$, Antonio Oliva ${ }^{2}$, Simone Grassi ${ }^{2}$, Ramon Brugada 1,3,4,5 and \\ Oscar Campuzano 1,3,4 (D)
}

1 Cardiovascular Genetics Center, University of Girona-IDIBGI, 17003 Salt, Spain; rbrugada@idibgi.org (R.B.); oscar@brugada.org (O.C.)

2 Section of Legal Medicine, Institute of Public Health, Catholic University, Fondazione Policlinico A. Gemelli, Istituto di Ricovero e Cura a Carattere Scientifico, 00168 Rome, Italy; antonio.Oliva@unicatt.it (A.O.); sgrassifb@gmail.com (S.G.)

3 Centro de Investigación Biomédica en Red de Enfermedades Cardiovasculares (CIBERCV), 28029 Madrid, Spain

4 Medical Science Department, School of Medicine, University of Girona, 17071 Girona, Spain

5 Cardiology Service, Hospital Josep Trueta, University of Girona, 17007 Girona, Spain

* Correspondence: mcoll@gencardio.com; Tel.: +34-872-98-70-87

Received: 21 January 2019; Accepted: 17 April 2019; Published: 23 April 2019

\begin{abstract}
Epilepsy is a common neurological disorder associated with increased morbidity and mortality. Sudden unexpected death in epilepsy, also known as SUDEP, is the main cause of death in patients with epilepsy. SUDEP has an incidence of 1.2 per 1000 person-years in adults and 0.2 per 1000 person-years in children. SUDEP accounts for $8-17 \%$ of deaths in patients with epilepsy. It is commonly associated with a history of generalized tonic-clonic seizures, and its risk may be increased by other factors such as postictal electroencephalographic suppression, prone sleeping position, altered heart rate variability, conduction abnormalities, gender, or antiepileptic medications. Recently, electrocardiograms, electroencephalograms, and imaging markers have helped clinicians stratify SUDEP risk and identify patients in need of close monitoring. However, the pathophysiology of SUDEP is likely multifactorial and still unknown. Improving the knowledge of SUDEP incidence, risk factors, and biomarkers can help design and implement effective prevention strategies.
\end{abstract}

Keywords: SUDEP; epilepsy; genetics

\section{Introduction}

Epilepsy is a common neurological disorder of the central nervous system characterized by recurrent seizures with or without convulsions [1]. Currently, seizures are classified into four groups: simple (status epilepticus), partial (seizures in infants and young adults), complex (generalized tonic-clonic seizures (GTCS)), and unclassified seizures. Those associated with an altered state of consciousness, particularly GTCS and uncontrolled repetitive seizures or status epilepticus, are associated with increased morbidity and mortality, especially in infants and young populations $[2,3]$.

In general, patients with epilepsy are two- to three-times more likely to die early than the general population [4]. Several possible causes of death have been reported in patients with epilepsy, including seizure complications, status epilepticus, or even suicide, but the main current cause is sudden unexpected death in epilepsy (SUDEP). Today, SUDEP is defined as a "sudden, unexpected, witnessed or unwitnessed, non-traumatic, and non-drowning death in patients with epilepsy with or without evidence for a seizure, and excluding documented status epilepticus, in which postmortem examination does not reveal a structural or toxicological cause of death" [5]. 
The concept of SUDEP was first defined in the 1990s based on whether an autopsy was performed and competing factors were present [6,7]. A new classification by Nashef et al. in 2012 helped refine SUDEP definitions and classification [5]. The authors introduced definite SUDEP plus and probable SUDEP plus, which are classifications that consider cases in which the individual had other concomitant conditions. The authors also defined near SUDEP, identifying resuscitated cases after a cardiopulmonary arrest of unidentified origin with survival of $>1 \mathrm{~h}$ (Table 1). Today, SUDEP is likely underestimated; thus, improved criteria to classify the cause of death would allow more accurate tracking of this condition. Devinsky et al. recently suggested additional clinical and pathological criteria for more consistent and reliable classification of epilepsy-related mortality [8]. Lamberts et al. [9] observed that $62 \%$ of SUDEP cases happened between midnight and noon, and that $58 \%$ of SUDEP cases were sleep-related. Further, they found that individuals whose deaths were associated with SUDEP were two-times more likely to have nocturnal seizures than those without SUDEP [9]. SUDEP occurs at night likely because of multiple factors, including both situational factors (absence of caregivers) and physiological modifications (circadian rhythms) [10].

Table 1. Proposed sudden unexpected death in epilepsy (SUDEP) definition and classification [5].

\begin{tabular}{|c|c|}
\hline Classification & Definition \\
\hline $\begin{array}{l}\text { Definite sudden unexpected death } \\
\text { in epilepsy (SUDEP) }\end{array}$ & $\begin{array}{l}\text { Sudden, unexpected, witnessed or unwitnessed, non-traumatic, and } \\
\text { non-drowning death that occurs in benign circumstances in an } \\
\text { individual with epilepsy, with or without evidence for a seizure, and } \\
\text { excludes documented status epilepticus, in which post-mortem } \\
\text { examination does not reveal a cause of death. }\end{array}$ \\
\hline Definite SUDEP plus & $\begin{array}{l}\text { Death satisfying criteria for definite SUDEP, if a concomitant condition } \\
\text { other than epilepsy is identified before or after death, if the death might } \\
\text { have been due to the combined effect of both conditions, and if autopsy } \\
\text { or direct observations or recording of the terminal event did not prove } \\
\text { the concomitant condition to be the cause of death. }\end{array}$ \\
\hline $\begin{array}{l}\text { Probable SUDEP or probable } \\
\text { SUDEP plus }\end{array}$ & Same definition as definite SUDEP or SUDEP plus, but without autopsy. \\
\hline Possible SUDEP & A competing cause of death is present. \\
\hline Near-SUDEP or near-SUDEP plus & $\begin{array}{l}\text { A patient with epilepsy who survives resuscitation for more than an } \\
\text { hour after cardiorespiratory arrest and has no structural cause identified } \\
\text { after investigation. }\end{array}$ \\
\hline Not SUDEP & A clear alternative cause of death is identified. \\
\hline Unclassified & Incomplete information available; impossible to classify. \\
\hline
\end{tabular}

\section{Epidemiology}

The current incidence of SUDEP remains undetermined, mainly because SUDEP and epilepsy are frequently underreported as possible or certain causes of death by clinicians and medical examiners [11]. This fact can be (partially) explained by two factors: the lack of accurate and proper knowledge of SUDEP among many practitioners, and the presence of only unspecific-and inconstant-signs in the autopsy (e.g., cortical dysplasia, hippocampal sclerosis, and eosinophilic neuronal change). SUDEP incidence varies depending on the sample population, age range, type of epilepsy, classification systems, diagnosis methods, and recorded cause of death [12-14]. Previous estimates indicate that SUDEP risk in young adults (aged 20-45 years) with epilepsy is up to 27-times higher than in the general population of the same age [15].

In 2017, the American Academy of Neurology (AAN) and American Epilepsy Society (AES) published a guideline on SUDEP, reporting an incidence per 1000 epilepsy person-years of 0.22 (95\% confidence interval (CI): 0.16-0.31) in children and 1.2 (95\% CI: 0.64-2.32) in adults-concluding that patients should be counseled that SUDEP risk is modest in children and small in adults [16]. 
In 2018, a meta-analysis of 45 cohorts of SUDEP cases estimated that the SUDEP pooled incidence rate was 0.0014 (95\% CI: 0.0009-0.0022) events per person-year. In particular, three variables-prospective design, mean patient age, and nature of the study population-explained $22 \%$ of the heterogeneity of the incidence rate [17].

As indicated, SUDEP incidence is highest among young adults, while it is considerably lower in the pediatric population. In individuals $<14$ years of age, SUDEP chiefly accounts for high-risk cases, such as individuals with major neurological impairment or injury [13]. If the onset of epileptic seizures occurs early and never fully remits, the risk of death is about $8 \%$ by 70 years of age. However, this risk might vary substantially in different populations, depending on seizure type and extent of seizure control [12]. In 2013, Holst et al. reported that the adjusted hazard ratio for death in young patients with epilepsy was 5.4-times higher than in the general population, and the adjusted hazard ratio for sudden death was 16.3-times higher than in the general population [15]. Consequently, epilepsy is associated with a significantly higher risk of death and sudden death in adults and children. Current AAN guidelines recommend that clinicians inform that SUDEP annually affects 0.2 per 1000 person-years in children with epilepsy and 1.2 per 1000 person-years in adults with epilepsy [16].

\section{Risk Factors}

The main cause of SUDEP remains unknown, and more than one mechanism seems to play a role. Several risk factors specific for SUDEP have been identified in case-control studies on SUDEP and non-SUDEP epilepsy deaths. Although identified risk factors vary due to the heterogeneity of the studies and because models cannot accurately predict the seizure risk for individual patients, some risk factors are recurrent. The strongest and most common risk factor for SUDEP is frequency of seizures, particularly GTCS $[13,18,19]$. Patients with $\geq 3$ GTCS per month have a 15 -fold increased risk of SUDEP. In addition, the presence of GTCS and not being seizure-free for 1-5 years are considered risk factors [16] (Table 2).

Table 2. SUDEP risk factors.

\begin{tabular}{cc}
\hline Risk & Factor \\
\hline High & Frequency of generalized tonic-clonic seizures (GTCS) \\
\hline Moderate & Presence of GTCS \\
& Not being seizure-free for $1-5$ years \\
& Not adding an antiepileptic drug when patients are medically refractory \\
Nocturnal supervision (risk reduction) \\
Use of nocturnal listening device (risk reduction)
\end{tabular}

Lack of proper/stable antiepileptic drug treatment and polytherapy have also been associated with increased SUDEP risk $[12,13,20]$. Further, the presence of someone who can provide assistance at night was reported to be protective in one case-control study [21]. Despite the lack of direct evidence, preventive interventions targeting these risk factors could reduce the risk of SUDEP [13].

SUDEP occurs in all ages, although patients who are 20-40 years old have a higher risk of SUDEP [22]. Both earlier age of onset and increased duration of epilepsy are risk factors for SUDEP [23]. SUDEP risk is doubtfully affected by ethnicity and gender, and it seems dependent on the population studied. Despite identified risk factors, however, part of the diagnosed population does not experience SUDEP, suggesting that other mechanisms are involved in the condition [14]. It is important to note that young people's risk of SUDEP is increased by intellectual disability, structural brain abnormalities, and abnormal neurological assessment [3]. Besides neurological conditions, psychiatric comorbidities also predispose to SUDEP [16].

A recent meta-analysis ranked the 10 leading risk factors derived from key cohort and populationbased studies (Table 3) [24]. 
Table 3. Principal risk factors for SUDEP (adapted from Reference [24]).

\begin{tabular}{ccc}
\hline Risk Factor & $\begin{array}{c}\text { Weighted Log Odds Ratio } \\
\text { (Adjusted Log OR } \div \text { Standard Error (SE)) }\end{array}$ & Reference \\
\hline >3 GTCS per year (versus 0 seizures) & 12.10 & Hesdorffer et al. [25] \\
>13 Seizures of any type in the past year & 4.20 & Nilsson et al. [26] \\
(versus 0-2 seizures) & 3.78 & Langan et al. [21] \\
No AED * treatment (versus 1-2 AEDs) & 3.24 & Nilsson et al. [26] \\
3 AEDs (versus 1) & 3.04 & Walczak et al. [27] \\
$\geq 3$ GTCS in past year (versus 0) & 2.39 & Langan et al. [21] \\
11-20 GTCS in the past 3 months (versus 0-5) & 2.29 & Nilsson et al. [26] \\
Age at onset of 0-15 years (versus >45 years) & 2.23 & Walczak et al. [27] \\
IQ <70 & 2.16 & Nilsson et al. [26] \\
3-5 changes in AEDs per year (versus 0) & 1.96 & Walczak et al. [27] \\
\hline >3 AEDs in the last visit (versus 0-2) &
\end{tabular}

* AED: antiepileptic drugs.

\section{Sudden Unexpected Death in Epilepsy (SUDEP) Pathophysiology}

Recent studies have extensively investigated the pathophysiology of SUDEP in different groups, proposing four main mechanisms for SUDEP: cardiac dysfunction, respiratory dysfunction, brainstem arousal system dysfunction, and dysregulation in the neurotransmitter and neuromodulator system [28]. Most results suggest a complex and multifactorial model. The MORTality in Epilepsy Monitoring Unit Study (MORTEMUS) study focused on deaths occurring during video electroencephalogram monitoring to ascertain the possible mechanisms of SUDEP on an international scale. The study results suggest that the crucial mechanism leading to SUDEP starts with an early, centrally mediated, severe alteration of both respiratory and cardiac functions after GTCS, which the authors consider as an early postictal neurovegetative breakdown. Depending on the intensity, this mechanism might lead to instant death or cardiorespiratory arrest after several minutes of altered cardiorespiratory function, most likely intensified by profound hypoxia. It has been hypothesized that intrinsic mechanisms leading to or associated with seizure termination are the origin of this centrally mediated neurovegetative breakdown and postictal generalized electroencephalogram (EEG) suppression [23].

\section{Genetics of SUDEP}

Definite evidence has recently emerged concerning genetic susceptibility to SUDEP, suggesting a highly polygenic contribution [18]. A gene associated with SUDEP should include a definite pathogenic alteration that causes epilepsy, increasing SUDEP risk [12]. Numerous neurocardiac genes have been identified as genomic biomarkers of disease severity and outcome, helping predict SUDEP incidence [19]. Moreover, several pathogenic alterations in different genes have been reported to increase SUDEP risk through different pathophysiological mechanisms. These genes encode proteins related to epilepsy and the cardiorespiratory system $[18,29]$. Until now, few genes have been analyzed in genetic testing (Table 4), but with next-generation sequencing and the low cost of these high-throughput technologies, candidate genes can now be interrogated to explore new genetic causes.

Few studies have examined possible genetic risk factors in SUDEP. In these cases, the limiting factor is sufficient DNA quality of samples collected during the life of the patient or extracted from postmortem blood. However, there is increasing awareness of the importance of collecting blood samples in unexplained sudden death to perform post-mortem genetic testing of main cardiac arrhythmia genes [20]. Further, in 2017, Bagnall et al. performed exome sequencing from degraded DNA derived from fixed postmortem tissues, which identified a de novo SCN1A frameshift variant in a patient with SUDEP [20]. This study shows the possibility to analyze historical collections of postmortem fixed tissues from SUDEP cases. 
Table 4. Genes associated with SUDEP (adapted from Reference [20]).

\begin{tabular}{ccc}
\hline Gene & Description & Evidence for Association with SUDEP \\
\hline SCN1A & Sodium Voltage-Gated Channel Alpha Subunit 1 & Animal model; de novo variants found in \\
SUDEP cases \\
SCN2A & Sodium Voltage-Gated Channel Alpha Subunit 2 & $\begin{array}{c}\text { De novo variants found in SUDEP cases } \\
\text { De novo variant found in SUDEP case }\end{array}$ \\
SCN5A & Voltage-Gated Sodium Channel Subunit Alpha Nav1.5 & Animal model; de novo variants found in \\
SCN8A & Sodium Voltage-Gated Channel Alpha Subunit 8 & SUDEP cases \\
KCNA1 & Potassium Voltage-Gated Channel Subfamily A Member 1 & Animal model; variant found in SUDEP case \\
KCNQ1 & Voltage-Gated Potassium Channel Subunit Kv7.1 & Variants found in SUDEP cases \\
KCNH2 & Voltage-Gated Potassium Channel Subunit Kv11.1 & Variants found in SUDEP cases \\
DEPDC5 & DEP Domain-Containing Protein 5 & De novo variants found in SUDEP cases \\
\hline
\end{tabular}

\subsection{Cardiac Arrhythmia Genes in SUDEP}

Epilepsy can have damaging effects on cardiac function, which may play an important role in the pathophysiology of SUDEP $[30,31]$. Epileptic seizures can induce malignant cardiac arrhythmias, possibly due to seizure-related effects on the autonomic nervous system [20].

Mutations of ion channel genes have a major role in the pathogenesis of several epilepsies, confirming that these are due to the impairment of ion channel function (channelopathies). Voltage-gated channels play an essential role in neuronal excitability and it is not surprising that most mutations associated with epilepsy have been identified in these genes [32].

In 2009, Aurlien et al. identified the first SCN5A mutation in a patient with idiopathic epilepsy, suggesting that ion channel mutations are co-expressed in the brain and heart and predispose to both epileptic seizures and cardiac arrhythmias [33]. In 2011, a larger retrospective analysis of autopsies of SUDEP cases in a forensic center in Australia during a 16-year period identified 86 SUDEP cases. The genetic analyses revealed six genetic mutations in voltage-gated ion channel genes KCNH2 and SCN5A, as previously reported in long QT syndrome (LQTS) [34]. Sequencing of a family of four hyperpolarization-activated cyclic nucleotide-gated cation channel genes (HCN1, HCN2, HCN3, and HCN4) in the same cohort identified three non-synonymous variants (Phe738Cys and Pro802Ser in HCN2, and Gly973Arg in HCN4).

The largest genetic study of SUDEP was done by Bagnall et al. in 2016 using exome sequencingbased analysis of 61 SUDEP cases [35]. They analyzed cardiac arrhythmia, respiratory control, and epilepsy genes, identifying four pathogenic and two candidate pathogenic variants of cardiac arrhythmia genes: a de novo SCN5A Ile397Val variant, a Gly924Ala and Arg744* nonsense variant in $K C N H 2$, and a Tyr662* nonsense variant in KCNQ1. The variants in KCNQ1 and KCNH2 were previously reported in patients diagnosed with LQTS, and these three variants were absent in more than 60,000 population controls. The de novo variant in SCN5A is located in a highly conserved transmembrane domain. All these variants are classified as likely pathogenic for LQTS. In addition, the variants were found in one coronial SUDEP case and three SUDEP cases from the Melbourne Epilepsy Research Centre cohort [20].

In 2016, our group performed next-generation sequencing on a cohort of 14 SUDEP cases using a custom resequencing panel, including genes previously related to SUDEP as well as new candidate genes. Four cases showed rare variants with complete segregation in SCN1A, FBN1, HCN1, SCN4A, and $E F H C 1$, and one case had a rare variant in KCNQ1 with incomplete penetrance. In four cases, rare variants were detected in $C A C N A 1 A, S C N 11 A, S C N 10 A$, and $K C N Q 1$ genes, although no familial segregation was performed due to a lack of DNA from relatives. This study confirmed the link between epilepsy, sudden death, and cardiac disease, and further identified new potential candidate genes for SUDEP: FBN1, HCN1, SCN4A, EFHC1, CACNA1A, SCN11A, and SCN10A [36].

The identification of all these gene variants previously associated with LQTS raises some questions about whether the variants are responsible for both epilepsy and sudden death, or if patients with or without gene variants have differing pathophysiology. Further, the identification of LQTS variants in individuals with SUDEP would allow the identification of variants in family members with or without 
epilepsy who are at risk of arrhythmia. SUDEP is also associated with variants and mutations of neurocardiac channelopathy genes [37]. This evidence could suggest some preventive measures to prevent sudden death, including avoidance of medications that may prolong the QT interval, taking antiarrhythmic drugs such as beta-blockers, and prophylactic interventions for possible lethal cardiac arrhythmias, such as implantable cardioverter defibrillators [20].

\subsection{Genetic Epilepsy Syndromes and SUDEP Risk}

Some genetic epilepsy syndromes have a high risk of SUDEP, and the associated pathogenic variants may be appropriate biomarkers [20]. Pathogenic alterations in SCN1A (associated with Dravet syndrome, a genetic epileptic encephalopathy in which a SCN1A loss-of-function mutation is found in $80 \%$ of cases) or in SCN8A (associated with early-infantile encephalopathy) are examples of variants co-expressed in both brain and heart that increase the risk of SUDEP [38]. However, it remains to be determined why these epilepsies caused by genetic variants should have a high risk of SUDEP.

A study by our group that included 20 epilepsy patients with personal or family history of heart rhythm disturbance/cardiac arrhythmia/sudden death identified four missense variants in epilepsy genes CDKL5, CNTNAP2, GRIN2A, and ADGRV1, with complete segregation within the family [39]. In 2016, Bagnall et al. [35] performed an exome-based analysis of cardiac arrhythmia, respiratory control, and epilepsy genes in SUDEP. They analyzed 61 SUDEP cases and found one previously described pathogenic mutation and five candidate pathogenic variants in DEPDC5. They also identified a variant in sodium channel gene $S C N 1 A$, related to genetic epilepsy plus febrile seizures and a rare cause of Brugada syndrome, and $S C N 2 A$, associated with epileptic encephalopathies [35].

\subsection{Respiratory Genes and SUDEP Risk}

The association between neuronal regulation of respiratory function and SUDEP came from functional in vivo models. DBA/1 and DBA/2 (Dilute Brown Non-Agouti) mice are useful animal models to study SUDEP because these mice exhibit generalized convulsive seizures followed by respiratory arrest [40]. Respiratory arrest can be prevented by treatments that activate serotonin (5-HT) receptors, as subtypes of 5-HT help regulate normal respiration [41]. Further, congenital heart hypoventilation syndrome is a disorder characterized by increased frequency of bradyarrhythmia and is mainly caused by expansion of an alanine repeat in $P H O X 2 B$. This gene could be a good target for SUDEP, although no studied SUDEP cases carry a variant in this gene [42]. Moreover, no genetic variants in respiratory control genes ( $A S C L 1, B D N F, E D N 3, G D N F$, and RET) were identified in exome analysis of 61 SUDEP cases [35].

\subsection{Future Directions}

Although considerable progress has been made in SUDEP in recent years, there is much work to be done on the genetic diagnosis of this condition. Several genes responsible for inherited channelopathies are linked to SUDEP, and several recently identified potential candidate genes with positive segregation indicate that a common cardiac neuron gene expression may underlie the basis of sudden death in epilepsy. Although in silico tools are being used to predict the possible pathogenicity and could help classify some variants, it is not recommended that these predictions be used as the sole source of evidence to make a clinical assertion. Moreover, larger cohorts as well as in vivo and in vitro studies will be required to ascertain the pathogenicity of these variants. Molecular genetic screening also needs to become an inherent part of the post-mortem examination in cases labeled as SUDEP. This genetic testing will enhance the ability to screen SUDEP victims' family members, who may be at-risk carriers of fatal cardiac disorders. Genetic interpretation requires multidisciplinary groups, including geneticists working together with clinicians, forensic pathologists, and genetic counselors. To best manage families, close interdisciplinary collaboration is essential. 


\section{New Biomarkers}

Although all individuals with epilepsy are at risk of SUDEP, the risk is not uniform across patient groups. Biomarkers are needed to identify the individual risk of SUDEP and thus personalize preventive interventions. Biomarkers might address innate risk factors of SUDEP, such as the genetic profile, as well as acquired risk factors (some of which might change over time), such as the level of post-GTCS brainstem dysfunction [43]. Three main tools are currently used: electrocardiogram (ECG), electroencephalogram (EEG), and imaging biomarkers (MRI and fMRI).

In 2013, Scorza et al. [44] first mentioned the term microRNA in SUDEP; microRNAs (miRNAs) are noncoding RNA molecules that play a critical role in gene expression regulation. These molecules are involved in important biological processes, are potential biomarkers for cardiovascular disorders, and can be detected in serum or plasma in a remarkably stable form. The authors suggested that expression pattern modifications of circulating miRNAs may be related to abnormal underlying cardiovascular processes, and could be identified and used as biomarkers for SUDEP [44]. In 2017, De Matteis et al. [45] presented a case of SUDEP in comparison with 10 autopsies of traumatic or asphyxia deaths. The authors analyzed expression profiles of several miRNAs (miR-301a-3p, miR-194-5p, miR-30b-5p, mIR-342-5p, and miR-4446-3p) from the plasma and temporal lobe, and identified a significant up-regulation of miR-301a-3p in the plasma (2.3-fold) and hippocampus (3.2-fold) of the SUDEP case compared with controls [45]. However, this potential biomarker still needs to be confirmed by additional cases.

\section{Prevention of SUDEP}

The main purpose of unravelling the incidence, risk factors, and biomarkers of SUDEP is to design and implement effective prevention strategies. Education is the first measure of prevention-treating physicians, primary care physicians, and neurologists must inform patients about risk factors for morbidity and mortality associated with medically refractory epilepsy, and about the importance of adhering to therapy and avoiding risky and/or unhealthy behaviors (e.g., sleeping in prone position, insufficient sleep, excessive drinking) [30]. Reported preventive measures include effective seizure control, nocturnal supervision, seizure monitoring, devices to protect the airway (e.g., anti-suffocation pillows), selective serotonin reuptake inhibitors, and other medications (caffeine and other adenosine antagonists have been proposed as hypothetical treatments) [28].

However, the evidence supporting these interventions is not robust [46,47]. The most effective prevention of SUDEP is likely complete remission of GTCS [48]. Usually, SUDEP occurs during sleep without supervision. Therefore, a preventive measure could involve using seizure and apnea detection devices to recognize the initial step of SUDEP and thus start resuscitation procedures as soon as possible. Cardiorespiratory resuscitation strategies have also been proposed as preventive measures for SUDEP. In 2008, Strzelczyk et al. described that implantation of pacemakers and defibrillators prevented ictal asystole in temporal lobe epilepsy patients [49].

\section{Conclusions}

SUDEP is the main cause of epilepsy-related premature mortality, especially in younger populations. Different types of epilepsy populations complicate the identification of SUDEP cases and, consequently, of its current incidence. Therefore, systematic methods to improve identification and better understand the causes of this condition are needed. Advancing our knowledge of SUDEP pathophysiologic mechanisms is the first step to reduce its incidence and elaborate new preventive strategies. At the same time, diffusion of knowledge about SUDEP must be supported and amplified inside scientific and medical communities to improve the quantity and quality of data available for research. In addition, biomarkers such as ECG, EEG, and imaging markers will help clinicians further stratify SUDEP risk and identify patients who need close monitoring. The identification of additional risk factors and biomarkers will help develop new preventive interventions for patients and their 
families. Ultimately, education of both families and clinicians as well as basic and clinical research and development of new treatments are needed to reduce the risk of SUDEP.

Author Contributions: Conception: M.C., O.C.; Literature Review: M.C., O.C., A.O. and S.G.; Writer: M.C., O.C.; Supervision: R.B.; Critical Review: R.B., A.O. and O.C.

Funding: This work was supported by Obra Social "La Caixa”, Fondo Investigacion Sanitaria (PI17/01690) from Instituto Salud Carlos III (ISCIII), and "Fundacio Privada Daniel Bravo Andreu". CIBERCV is an initiative of the ISCIII, Spanish Ministry of Economy and Competitiveness. This work has been supported by Fondi Linea D1-Università Cattolica del Sacro Cuore, Italy.

Conflicts of Interest: The authors declare no conflict of interest.

\section{Abbreviations}

$\begin{array}{ll}\text { SUDEP } & \text { Sudden unexpected death in epilepsy } \\ \text { GTCS } & \text { Generalized tonic-clonic seizures } \\ \text { AED } & \text { Antiepileptic drugs } \\ \text { LQTS } & \text { Long QT syndrome } \\ \text { ECG } & \text { Electrocardiogram } \\ \text { EEG } & \text { Electroencephalogram }\end{array}$

\section{References}

1. Suruchi, V.D. Epilepsy-a comprehensive review. Int. J. Pharm. Res. Rev. 2013, 2, 61-80.

2. Fazel, S.; Wolf, A.; Langstrom, N.; Newton, C.R.; Lichtenstein, P. Premature mortality in epilepsy and the role of psychiatric comorbidity: A total population study. Lancet 2013, 382, 1646-1654. [CrossRef]

3. Berg, A.T.; Nickels, K.; Wirrell, E.C.; Geerts, A.T.; Callenbach, P.M.; Arts, W.F.; Rios, C.; Camfield, P.R.; Camfield, C.S. Mortality risks in new-onset childhood epilepsy. Pediatrics 2013, 132, 124-131. [CrossRef] [PubMed]

4. Appleton, R.E. Sudden, unexpected death in epilepsy in children. Seizure 1997, 6, 175-177. [CrossRef]

5. Nashef, L.; So, E.L.; Ryvlin, P.; Tomson, T. Unifying the definitions of sudden unexpected death in epilepsy. Epilepsia 2012, 53, 227-233. [CrossRef]

6. Annegers, J.F. United States perspective on definitions and classifications. Epilepsia 1997, 38, S9-S12. [CrossRef] [PubMed]

7. Nashef, L. Sudden unexpected death in epilepsy: Terminology and definitions. Epilepsia 1997, 38, S6-S8. [CrossRef]

8. Devinsky, O.; Bundock, E.; Hesdorffer, D.; Donner, E.; Moseley, B.; Cihan, E.; Hussain, F.; Friedman, D. Resolving ambiguities in SUDEP classification. Epilepsia 2018, 59, 1220-1233. [CrossRef]

9. Lamberts, R.J.; Thijs, R.D.; Laffan, A.; Langan, Y.; Sander, J.W. Sudden unexpected death in epilepsy: People with nocturnal seizures may be at highest risk. Epilepsia 2012, 53, 253-257. [CrossRef]

10. Purnell, B.S.; Thijs, R.D.; Buchanan, G.F. Dead in the Night: Sleep-Wake and Time-Of-Day Influences on Sudden Unexpected Death in Epilepsy. Front. Neurol. 2018, 9, 1079. [CrossRef] [PubMed]

11. Flannery, R.B., Jr.; Lomke, E. SUDEP and Grief: Overview and Current Issues. Psychiatr. Q. 2018. [CrossRef]

12. Devinsky, O.; Hesdorffer, D.C.; Thurman, D.J.; Lhatoo, S.; Richerson, G. Sudden unexpected death in epilepsy: Epidemiology, mechanisms, and prevention. Lancet Neurol. 2016, 15, 1075-1088. [CrossRef]

13. Shankar, R.; Donner, E.J.; McLean, B.; Nashef, L.; Tomson, T. Sudden unexpected death in epilepsy (SUDEP): What every neurologist should know. Epileptic Disord. Int. Epilepsy J. Videotape 2017, 19, 1-9.

14. Dlouhy, B.J.; Gehlbach, B.K.; Richerson, G.B. Sudden unexpected death in epilepsy: Basic mechanisms and clinical implications for prevention. J. Neurol. Neurosurg. Psychiatry 2016, 87, 402-413. [CrossRef]

15. Holst, A.G.; Winkel, B.G.; Risgaard, B.; Nielsen, J.B.; Rasmussen, P.V.; Haunso, S.; Sabers, A.; Uldall, P.; Tfelt-Hansen, J. Epilepsy and risk of death and sudden unexpected death in the young: A nationwide study. Epilepsia 2013, 54, 1613-1620. [CrossRef]

16. Harden, C.; Tomson, T.; Gloss, D.; Buchhalter, J.; Cross, J.H.; Donner, E.; French, J.A.; Gil-Nagel, A.; Hesdorffer, D.C.; Smithson, W.H.; et al. Practice Guideline Summary: Sudden Unexpected Death in Epilepsy Incidence Rates and Risk Factors: Report of the Guideline Development, Dissemination, and Implementation Subcommittee of the American Academy of Neurology and the American Epilepsy Society. Epilepsy Curr. 2017, 17, 180-187. [CrossRef] 
17. Saetre, E.; Abdelnoor, M. Incidence rate of sudden death in epilepsy: A systematic review and meta-analysis. Epilepsy Behav. 2018, 86, 193-199. [CrossRef]

18. Leu, C.; Balestrini, S.; Maher, B.; Hernandez-Hernandez, L.; Gormley, P.; Hamalainen, E.; Heggeli, K.; Schoeler, N.; Novy, J.; Willis, J.; et al. Genome-wide Polygenic Burden of Rare Deleterious Variants in Sudden Unexpected Death in Epilepsy. EBioMedicine 2015, 2, 1063-1070. [CrossRef]

19. Manolis, T.A.; Manolis, A.A.; Melita, H.; Manolis, A.S. Sudden unexpected death in epilepsy: The neurocardio-respiratory connection. Seizure 2018, 64, 65-73. [CrossRef]

20. Bagnall, R.D.; Ingles, J.; Yeates, L.; Berkovic, S.F.; Semsarian, C. Exome sequencing-based molecular autopsy of formalin-fixed paraffin-embedded tissue after sudden death. Genet. Med. 2017, 19, 1127-1133. [CrossRef]

21. Langan, Y.; Nashef, L.; Sander, J.W. Case-control study of SUDEP. Neurology 2005, 64, 1131-1133. [CrossRef]

22. Tomson, T.; Walczak, T.; Sillanpaa, M.; Sander, J.W. Sudden unexpected death in epilepsy: A review of incidence and risk factors. Epilepsia 2005, 46 (Suppl. 11), 54-61. [CrossRef]

23. Ryvlin, P.; Nashef, L.; Lhatoo, S.D.; Bateman, L.M.; Bird, J.; Bleasel, A.; Boon, P.; Crespel, A.; Dworetzky, B.A.; Hogenhaven, H.; et al. Incidence and mechanisms of cardiorespiratory arrests in epilepsy monitoring units (MORTEMUS): A retrospective study. Lancet Neurol. 2013, 12, 966-977. [CrossRef]

24. DeGiorgio, C.M.; Curtis, A.; Hertling, D.; Moseley, B.D. Sudden unexpected death in epilepsy: Risk factors, biomarkers, and prevention. Acta Neurol. Scand. 2018. [CrossRef]

25. Hesdorffer, D.; Beghi, E. ILAE epidemiology commission report: Introduction to the supplement. Epilepsia 2011, 52 (Suppl. 7), 1.

26. Nilsson, L.; Farahmand, B.Y.; Persson, P.G.; Thiblin, I.; Tomson, T. Risk factors for sudden unexpected death in epilepsy: A case-control study. Lancet 1999, 353, 888-893. [CrossRef]

27. Walczak, T.S.; Leppik, I.E.; D’Amelio, M.; Rarick, J.; So, E.; Ahman, P.; Ruggles, K.; Cascino, G.D.; Annegers, J.F.; Hauser, W.A. Incidence and risk factors in sudden unexpected death in epilepsy: A prospective cohort study. Neurology 2001, 56, 519-525. [CrossRef]

28. Ruthirago, D.; Julayanont, P.; Karukote, A.; Shehabeldin, M.; Nugent, K. Sudden unexpected death in epilepsy: Ongoing challenges in finding mechanisms and prevention. Int. J. Neurosci. 2018. [CrossRef]

29. Thom, M.; Boldrini, M.; Bundock, E.; Sheppard, M.N.; Devinsky, O. Review: The past, present and future challenges in epilepsy-related and sudden deaths and biobanking. Neuropathol. Appl. Neurobiol. 2018, 44, 32-55. [CrossRef]

30. Ellis, S.P., Jr.; Szabo, C.A. Sudden Unexpected Death in Epilepsy: Incidence, Risk Factors, and Proposed Mechanisms. Am. J. Forensic Med. Pathol. 2018, 39, 98-102. [CrossRef]

31. De Llano, C.T.; Campuzano, O.; Perez-Serra, A.; Mademont, I.; Coll, M.; Allegue, C.; Iglesias, A.; Partemi, S.; Striano, P.; Oliva, A.; et al. Further evidence of the association between LQT syndrome and epilepsy in a family with KCNQ1 pathogenic variant. Seizure 2015, 25, 65-67.

32. Wang, S.; Li, L.; Tao, R.; Gao, Y. Ion channelopathies associated genetic variants as the culprit for sudden unexplained death. Forensic Sci. Int. 2017, 275, 128-137. [CrossRef]

33. Aurlien, D.; Leren, T.P.; Tauboll, E.; Gjerstad, L. New SCN5A mutation in a SUDEP victim with idiopathic epilepsy. Seizure 2009, 18, 158-160. [CrossRef]

34. Tu, E.; Bagnall, R.D.; Duflou, J.; Semsarian, C. Post-mortem review and genetic analysis of sudden unexpected death in epilepsy (SUDEP) cases. Brain Pathol. 2011, 21, 201-208. [CrossRef]

35. Bagnall, R.D.; Crompton, D.E.; Petrovski, S.; Lam, L.; Cutmore, C.; Garry, S.I.; Sadleir, L.G.; Dibbens, L.M.; Cairns, A.; Kivity, S.; et al. Exome-based analysis of cardiac arrhythmia, respiratory control, and epilepsy genes in sudden unexpected death in epilepsy. Ann. Neurol. 2016, 79, 522-534. [CrossRef]

36. Coll, M.; Allegue, C.; Partemi, S.; Mates, J.; Del Olmo, B.; Campuzano, O.; Pascali, V.; Iglesias, A.; Striano, P.; Oliva, A.; et al. Genetic investigation of sudden unexpected death in epilepsy cohort by panel target resequencing. Int. J. Leg. Med. 2016, 130, 331-339. [CrossRef]

37. Moghimi, N.; Lhatoo, S.D. Sudden unexpected death in epilepsy or voodoo heart: Analysis of heart/brain connections. Curr. Cardiol. Rep. 2013, 15, 424. [CrossRef]

38. Mantegazza, M.; Curia, G.; Biagini, G.; Ragsdale, D.S.; Avoli, M. Voltage-gated sodium channels as therapeutic targets in epilepsy and other neurological disorders. Lancet Neurol. 2010, 9, 413-424. [CrossRef]

39. Coll, M.; Striano, P.; Ferrer-Costa, C.; Campuzano, O.; Mates, J.; Del Olmo, B.; Iglesias, A.; Perez-Serra, A.; Mademont, I.; Pico, F.; et al. Targeted next-generation sequencing provides novel clues for associated epilepsy and cardiac conduction disorder/SUDEP. PLOS ONE 2017, 12, e0189618. [CrossRef] 
40. Feng, H.J.; Faingold, C.L. Abnormalities of serotonergic neurotransmission in animal models of SUDEP. Epilepsy Behav. 2017, 71, 174-180. [CrossRef]

41. Uteshev, V.V.; Tupal, S.; Mhaskar, Y.; Faingold, C.L. Abnormal serotonin receptor expression in DBA/2 mice associated with susceptibility to sudden death due to respiratory arrest. Epilepsy Res. 2010, 88, 183-188. [CrossRef] [PubMed]

42. Bagnall, R.D.; Crompton, D.E.; Cutmore, C.; Regan, B.M.; Berkovic, S.F.; Scheffer, I.E.; Semsarian, C. Genetic analysis of $P H O X 2 B$ in sudden unexpected death in epilepsy cases. Neurology 2014, 83, 1018-1021. [CrossRef] [PubMed]

43. Devinsky, O.; Ryvlin, P.; Friedman, D. Preventing Sudden Unexpected Death in Epilepsy. JAMA Neurol. 2018, 75, 531-532. [CrossRef]

44. Scorza, F.A.; Cendes, F.; Cavalheiro, E.A.; Lopes-Cendes, I. Sudden unexpected death in epilepsy: Small RNAs raise expectations. Epilepsy Behav. 2013, 29, 591-593. [CrossRef]

45. De Matteis, M.; Cecchetto, G.; Munari, G.; Balsamo, L.; Paola Gardiman, M.; Giordano, R.; Viel, G.; Fassan, M. Circulating miRNAs expression profiling in drug-resistant epilepsy: Up-regulation of miR-301a-3p in a case of sudden unexpected death. Leg. Med. 2018, 33, 5. [CrossRef] [PubMed]

46. Ryvlin, P.; Nashef, L.; Tomson, T. Prevention of sudden unexpected death in epilepsy: A realistic goal? Epilepsia 2013, 54 (Suppl. 2), 23-28. [CrossRef] [PubMed]

47. Tomson, T.; Surges, R.; Delamont, R.; Haywood, S.; Hesdorffer, D.C. Who to target in sudden unexpected death in epilepsy prevention and how? Risk factors, biomarkers, and intervention study designs. Epilepsia 2016, 57 (Suppl. 1), 4-16. [CrossRef] [PubMed]

48. Fountain, N.B.; Van Ness, P.C.; Swain-Eng, R.; Tonn, S.; Bever, C.T., Jr. Quality improvement in neurology: AAN epilepsy quality measures: Report of the Quality Measurement and Reporting Subcommittee of the American Academy of Neurology. Neurology 2011, 76, 94-99. [CrossRef] [PubMed]

49. Strzelczyk, A.; Bauer, S.; Knake, S.; Oertel, W.H.; Hamer, H.M.; Rosenow, F. Ictal asystole in temporal lobe epilepsy before and after pacemaker implantation. Epileptic Disord. Int. Epilepsy J. Videotape 2008, 10, $39-44$.

(C) 2019 by the authors. Licensee MDPI, Basel, Switzerland. This article is an open access article distributed under the terms and conditions of the Creative Commons Attribution (CC BY) license (http://creativecommons.org/licenses/by/4.0/). 